\title{
Compact portable biosensor for arsenic detection in aqueous samples with Escherichia coli bioreporter cells
}

\author{
Frederic Truffer, ${ }^{1, a)}$ Nina Buffi, ${ }^{2}$ Davide Merulla, ${ }^{3}$ Siham Beggah, ${ }^{3}$ Harald van Lintel, ${ }^{2}$ \\ Philippe Renaud, ${ }^{2}$ Jan Roelof van der Meer, ${ }^{3}$ and Martial Geiser ${ }^{1}$ \\ ${ }^{1}$ Institute of Systems Engineering, University of Applied Sciences and Arts Western Switzerland Valais, \\ Sion, Switzerland \\ ${ }^{2}$ Laboratory of Microsystems Engineering, Ecole Polytechnique Fédérale Lausanne, EPFL-STI-LMIS, \\ Station 17, CH-1015 Lausanne, Switzerland \\ ${ }^{3}$ Department of Fundamental Microbiology, University of Lausanne, Switzerland
}

(Received 3 October 2013; accepted 13 January 2014; published online 31 January 2014)

\begin{abstract}
We present a compact portable biosensor to measure arsenic $A s(I I I)$ concentrations in water using Escherichia coli bioreporter cells. Escherichia coli expresses green fluorescent protein in a linearly dependent manner as a function of the arsenic concentration (between 0 and $100 \mu \mathrm{g} / \mathrm{L}$ ). The device accommodates a small polydimethylsiloxane microfluidic chip that holds the agarose-encapsulated bacteria, and a complete optical illumination/collection/detection system for automated quantitative fluorescence measurements. The device is capable of sampling water autonomously, controlling the whole measurement, storing and transmitting data over GSM networks. We demonstrate highly reproducible measurements of arsenic in drinking water at 10 and $50 \mu \mathrm{g} / \mathrm{L}$ within 100 and $80 \mathrm{~min}$, respectively. @ 2014 AIP Publishing LLC. [http://dx.doi.org/10.1063/1.4863333]
\end{abstract}

\section{INTRODUCTION}

Arsenic $(A s)$ contamination of potable water is a serious problem affecting over 137 million people in more than 70 countries. ${ }^{1}$ As affects nearly all organ systems in the human body, causes skin necrosis and chronic exposure results in the development of cancer. ${ }^{2}$ The maximum As concentration in drinking water recommended by the US-Environmental Protection Agency and the World Health Organization ${ }^{3}$ is $10 \mu \mathrm{g} / \mathrm{L}$. The most frequently found forms of arsenic in groundwater are $A s(V)$ and $A s(I I I)$, which can originate from natural rocks and sediments, or from industrial waste, mining or pesticides.

There are several instruments and techniques available to measure As but these are often bulky, expensive to operate or maintain, and require skilled laboratory staff. Examples include atomic fluorescence spectroscopy, ${ }^{4}$ graphite furnace atomic absorption, microcantilever sensors, electrophoresis techniques, hydride generation atomic absorption spectroscopy, inductively coupled plasma-atomic emission spectrometry, surface enhanced Raman spectroscopy, laser induced breakdown spectroscopy, and inductively coupled plasma-mass spectrometry. ${ }^{5}$

Accurate and rapid field assays for arsenic would be extremely important for avoiding, e.g., contaminated local water pumps, and thus for mitigating arsenic intoxication. They should be relatively inexpensive, allow large number of screenings in a short time, be compact, portable, and easy to use, while maintaining sufficient accuracy at and below the recommended As thresholds. A number of methods described in literature include:

1. Colorimetric tests based on the Gutzeit method. ${ }^{6}$ In this test the sample is mixed with a reducing agent $(\mathrm{Zn})$ that

\footnotetext{
a)frederic.truffer@hevs.ch
}

reduces $\mathrm{As}$ to $\mathrm{AsH}_{3}$, which is volatile, and evaporates from solution. The arsine gas reacts with mercuric bromide on an impregnated paper and the resulting color change is representative for the concentration of the dissolved As. Unfortunately, compounds such as tellurium, selenium, and sulfur can falsify the results, colors are difficult to interpret and the method releases toxic mercuric. ${ }^{7}$ Many research groups are trying to optimize this basic method to improve the detection limit, to eliminate the interference from other compounds and to minimize the toxic waste/gas production.

2. Anodic stripping voltammetry ${ }^{8}$ is a technique in which the sample is acidified to $\mathrm{pH} 2$, and $A s$ is reduced on a thin gold-film covered electrode. The process is subsequently reversed, and the electric current required to remove the As from the electrode is measured. The response is compared to that with known standard As solutions. Interferences with other compounds in the water samples are possible.

3. Bacterial bioreporter technology was presented as a radically different method for detecting $A s$ in aqueous samples and food stuffs. With this technology, genetically engineered bacteria react to the As present in a sample and produce an easily detectable protein activity in response. The advantages of the technology are the easy operation and preparation of the (living) cells, the sensitivity of the cells, with response well below $10 \mu \mathrm{g} / \mathrm{L}$, and the variety of reporter "outputs" possible. For example, As-bioreporters exist which produce fluorescence, bioluminescence, visible colors, current or $\mathrm{pH}$ changes. ${ }^{10}$ Comparative field assays with extremely simple bacterial bioreporter technology demonstrated excellent quantification and low falsenegative sample measurements. ${ }^{11,12}$ Since bioreporter assays still require a certain degree of manipulation 


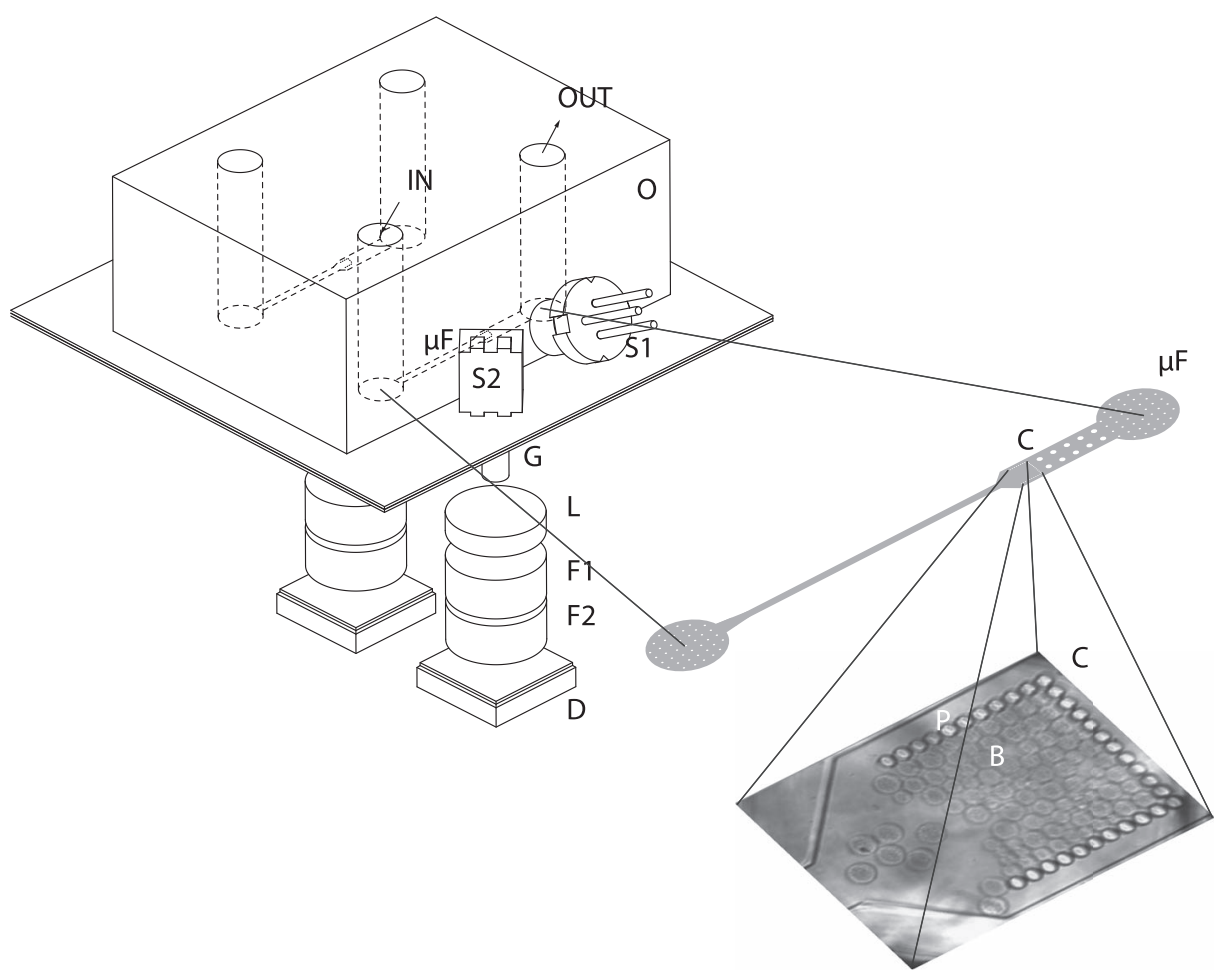

FIG. 1. PDMS block with the tubing (IN, OUT), illumination (S1, S2), detection (D), microfluidic channel ( $\mu$ F), and cage (C) to trap agarose beads (B) filled with bacteria. For description of the other components, see the main text.

of the cells, we sought to design and produce a standalone device in which cells would be embedded using microfluidic cartridges, and that would further automatically sample, read-out and record the reporter cell's response.

\section{MATERIALS AND METHODS}

\section{A. Bioreporter cells}

Details of the Escherichia coli based As-sensitive bioreporter cells have been described extensively in Ref. 13. Here, we used Escherichia coli strain 1598, which carries the plasmid $p P R O B E-A r s R-A B S$, and produces green fluorescent protein (GFP) in response to $A s(I I I)$ and $A s(V) .{ }^{13}$ Cells were grown to exponential phase and then embedded in agarose mini-beads, which were frozen in 15\% glycerol at $-80{ }^{\circ} \mathrm{C}$, as described previously. ${ }^{9}$ For assays, the cells-in-beads were thawed, equilibrated for $20 \mathrm{~min}$ at room temperature, and then filled into the microfluidic chip. ${ }^{9}$ Cellular response was recorded in MOPS medium with $10 \mathrm{mM}$ glucose, as described. ${ }^{9}$

\section{B. System description}

The system is based on a microfluidic polydimethylsiloxane (PDMS) block ${ }^{9}$ with two parallel channels (Figure 1). A stainless steel mold ensures precise dimensions of the block $\left(15 \times 20 \times 8 \mathrm{~mm}^{3}\right)$ and positions the silicon master to $\pm 0.01 \mathrm{~mm}$. The two longer sides of the mold are polished so that the PDMS (Sylgard $^{\complement} 184$ from Dow Corning, USA) surfaces are optically transparent. The block is bonded us- ing plasma treatment on a $150 \mu \mathrm{m}$ thick regular microscope cover slip. It is then clamped into a frame that positions the cage $\mathrm{C}$ over the fluorescence detector, which contains two light sources $\mathrm{S} 1$ and $\mathrm{S} 2$ (Figure 1). S2 is a green SMD LED $\left(520 \mathrm{~nm}\right.$, Osram) that illuminates the cage $\mathrm{C}\left(500 \mu \mathrm{m}^{2}\right)$ at an angle of $85^{\circ}$. Scattered light is measured with detector D. Assuming that most of the scattering is due to the cells-in-beads (B), a sudden change in light scatter indicates a problem in the microfluidic system (either changes in the number of beads or air bubbles trapped in the cage). Light scattering thus serves as an internal control for normal operation of the device with the cells-in-beads. A laser diode ( $445 \mathrm{~nm}, 60 \mathrm{~mW}$, Soraa) provides the excitation light $\mathrm{S} 1$. A part of the emitted fluorescence light is collected by the fiber G $(1200 \mu \mathrm{m}$ NA 0.39 , Thorlabs) located just under the cage and collimated by a lens $\mathrm{L}$ ( $\mathrm{f}=2.75 \mathrm{~mm}$, Thorlabs). Two identical $35 \mathrm{~nm}$ band pass filters F1 and F2 (FF01-520/35, Semrock) block the excitation light, so that only fluorescence light is detected by the photodiode D (S10357-01, Hamamatsu). Dedicated electronics amplify the signal and send it to a microprocessor (MPS430 16 bit, Texas Instruments). An EPROM (24LC256, Microchip) saves default parameters. The system can be connected to a computer with a USB interface and commands/results can be sent/received through a dedicated terminal. A GSM modem allows the control of the process by sending commands with a mobile phone and receiving results. A battery (12 V, 7.2 Ah) provides electrical power. Two pumps (100-PH, Williamson Manufacturing) with a gear box 1:3000 with a motor (MFA Motors) guarantee a continuous flow of $100 \mu \mathrm{l} / \mathrm{h}$ of the sampling water over the cells in the chip (see Figure 2). 


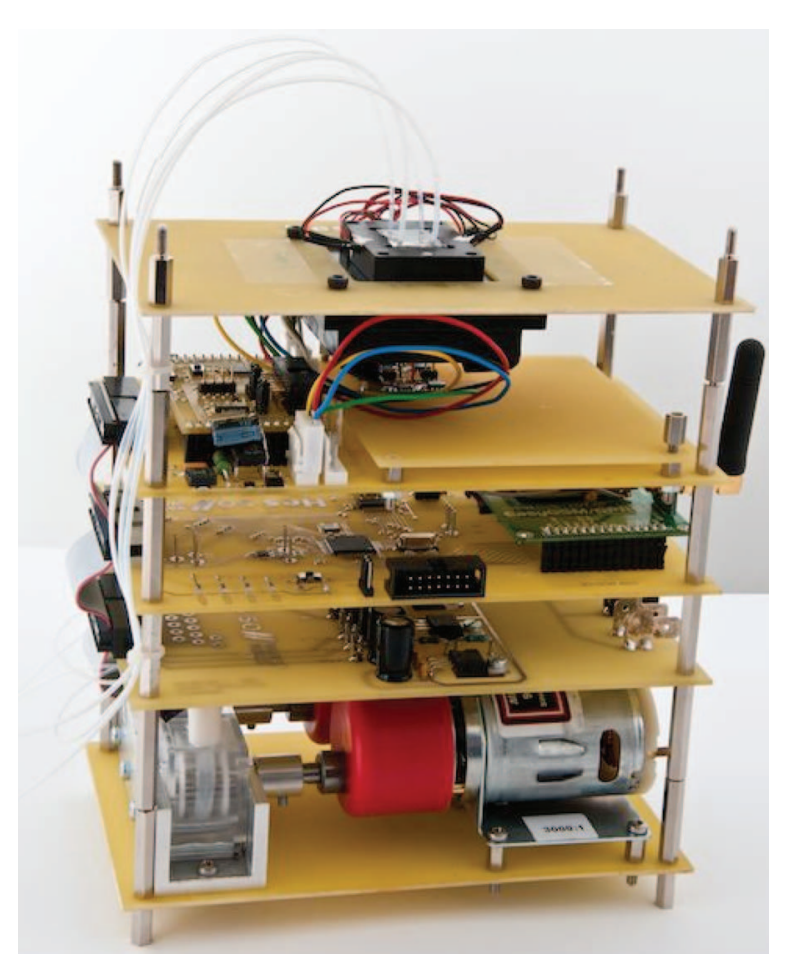

FIG. 2. The overall biosensor device with the microfluidic cell chip on top $\left(10 \times 16 \times 25 \mathrm{~cm}^{3}\right)$. The device uses a $12 \mathrm{~V}$ power supply and communicates via GSM or via USB with a computer.

\section{Measurements}

The determination of As in an aqueous sample consisted of a set of 10 measurements with 20 min interval. Aqueous $A s$ standards were prepared freshly from a concentrated stock solution (50 $\mathrm{mM} \mathrm{NaAsO}_{2}$, Merck) by dilution with 3(N-morpholino) propanesulfonic acid (MOPS) medium, tap water and $30 \mu \mathrm{l}$ of rich Luria-Bertani (LB) medium to obtain solutions of $10 \mu \mathrm{g} / \mathrm{L}$ and $50 \mu \mathrm{g} / \mathrm{L} A s(I I I)$. For negative controls a similar mixture of MOPS, tap water and LB was used.

For each run, a new microfluidic PDMS chip was loaded with beads (time 0), which were retained in the cage $\mathrm{C}$ (Figure 1). All fluidic components were connected and the cells-in-beads were exposed to the aqueous sample containing $A s$ at room temperature. The first measurement was taken 20 min after induction to be sure that the beads in the cage and the flow conditions were stable. Intensity and duration of excitation light were chosen such that no photo bleaching occurred. Directly after each fluorescence measurement with light from the laser to determine the As concentration, the scattered light from the LED was measured. All measurements were performed in a laboratory environment with a temperature of $20^{\circ} \mathrm{C}$. Data were analyzed using the programming language R. ${ }^{14}$

\section{RESULTS}

Aqueous solutions containing As in different concentrations $(0 \mu \mathrm{g} / \mathrm{L}, 10 \mu \mathrm{g} / \mathrm{L}$, and $50 \mu \mathrm{g} / \mathrm{L})$ were measured in the two parallel channels at the same time. Figure 3 shows average values for $10 \mu \mathrm{g} / \mathrm{L}$ and $50 \mu \mathrm{g} / \mathrm{L}$ from eight independent measurements, for $0 \mu \mathrm{g} / \mathrm{L}$ from four independent runs. Error

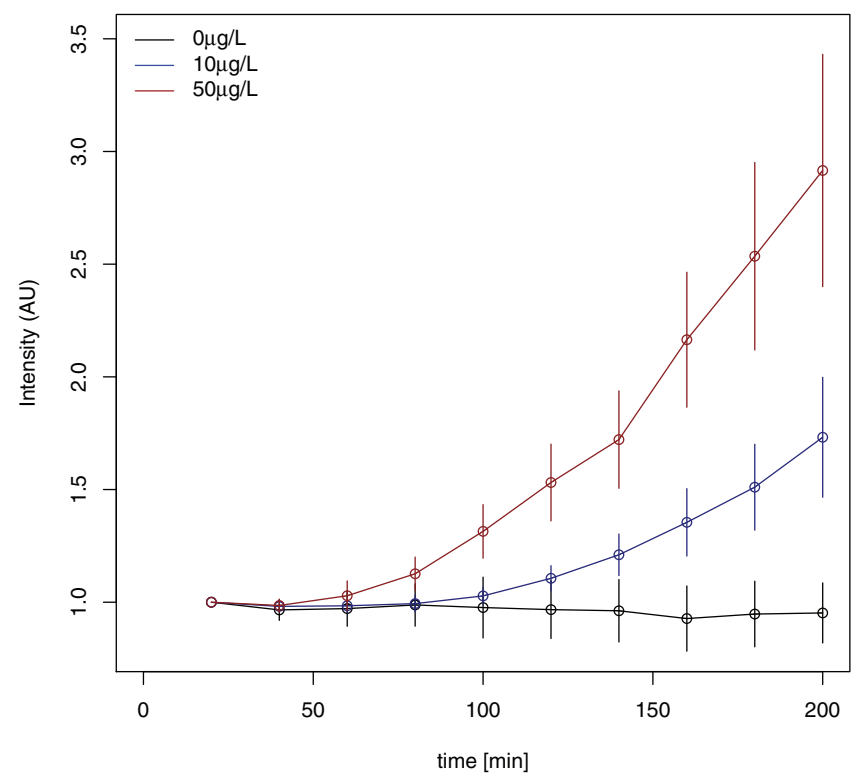

FIG. 3. Measurements of different $A s$ concentrations $0 \mu \mathrm{g} / \mathrm{L}, 10 \mu \mathrm{g} / \mathrm{L}$, and $50 \mu \mathrm{g} / \mathrm{L}$.

bars display the calculated $95 \%$ confidence intervals. All results were normalized to the signal level at time $20 \mathrm{~min}$. Measurements with single cell-in-bead batches stored at $-80{ }^{\circ} \mathrm{C}$ were thus extremely reproducible. The shortest possible time to distinguish $50 \mu \mathrm{g} \mathrm{As} / \mathrm{L}$ was $80 \mathrm{~min}$, and for $10 \mu \mathrm{g} \mathrm{As} / \mathrm{L}$ 120 min (Figure 3).

\section{CONCLUSION}

We have developed a simple electronic device with a small optical setup to measure GFP fluorescence from bacterial reporter cells in two parallel channels with a similar sensitivity. Such a device has a great potential in field measurements because of the low cost and the compact size compared to, e.g., conventional systems used in laboratories.

\section{ACKNOWLEDGMENTS}

The authors gratefully acknowledge support from the Swiss National Science Foundation, Sinergia program, Contract Nos. CRSI20-122689/CRII2-141845, and the Nano-Tera program, project LiveSense.

\footnotetext{
${ }^{1}$ Arsenic in drinking water seen as threat, Associated Press. 2007-08-30.

${ }^{2}$ Subcommittee to Update the 1999 Arsenic in Drinking Water Report, Committee on Toxicology, Board on Environmental Studies and Toxicology, National Research Council, Arsenic in Drinking Water: 2001 Update (The National Academies Press, 2001).

${ }^{3}$ World Health Organization, "Arsenic in drinking water," Fact Sheet No. 210, 2001.

${ }^{4}$ J. L. Gomez-Ariza, D. Sanchez-Rodas, I. Giraldez, and E. Morales, Talanta 51, 257-268 (2000).

${ }^{5}$ M. Leermakers, W. Baeyens, M. De Gieter, B. Smedts, C. Meert, H. C. De Bisschop, R. Morabito, and P. Quevauviller, TrAC, Trends Anal. Chem. 25, 1 (2006).

${ }^{6}$ D. G. Kinniburgh and W. Kosmus, Talanta 58, 165-180 (2002).

${ }^{7}$ A. Hussam, M. Alauddin, A. H. Khan, S. B. Rasul, and A. K. M. Munir, Environ. Sci. Technol. 33, 3686-3688 (1999).

${ }^{8}$ P. Salaün, B. Planer-Friedrich, and C. M. G. van den Berg, Anal. Chim. Acta 585, 312-322 (2007).
} 
${ }^{9}$ N. Buffi, D. Merulla, J. Beutier, F. Barbaud, S. Beggah, H. van Lintel, P. Renaud, and J. R. van der Meer, Lab Chip 11, 2369-2377 (2011).

${ }^{10}$ D. Merulla, N. Buffi, S. Beggah, F. Truffer, M. Geiser, P. Renaud, and J. van der Meer, Curr. Opin. Biotechnol. 24, 534-541 (2013).

${ }^{11}$ K. Siegfried, C. Endes, A. F. Bhuiyan, A. Kuppardt, J. Mattusch, J. R. van der Meer, A. Chatzinotas, and H. Harms, Environ. Sci. Technol. 46, 3281-3287 (2012)
${ }^{12}$ P. T. Trang, M. Berg, P. H. Viet, N. Van Mui, and J. R. van der Meer, Environ. Sci. Technol. 39, 7625-7630 (2005).

${ }^{13}$ J. Stocker, D. Balluch, M. Gsell, H. Harms, J. S. Feliciano, S. Daunert, K. A. Malik, and J. R. van der Meer, Environ. Sci. Technol. 37, 4743-4750 (2003)

${ }^{14}$ See http://www.R-project.org/ for R Core Team (2012), R: A Language and Environment for Statistical Computing, R Foundation for Statistical Computing, Vienna, Austria. 